\title{
A case of ganglioneuroma arising in the pituitary fossa
}

\author{
DAVID M. ROBERTSON AND ROBERT F. HETHERINGTON \\ From the Departments of Pathology and Surgery, \\ Queen's University and Kingston General Hospital, Kingston, Ontario, Canada
}

Primary tumours arising in neural tissue located in the sella turcica are infrequently encountered. The pars nervosa of the pituitary gland contains glial cells ('pituicytes'), generally thought to be modified astrocytes, and axons derived from the neurones of the supra-optic and paraventricular nuclei, but is devoid of neurones. The majority of reported neurohypophyseal tumours have been gliomas. Scothorne (1955) described a piloid astrocytoma confined to the posterior lobe of the pituitary gland, and reviewed several similar previously reported cases; since some of these had also involved hypothalamic structures their site of origin was open to question. The term 'infundibuloma' was proposed for gliomas of the neurohypophysis by Globus (1942). However, Russell and Rubinstein (1959) regarded these tumours as identical to pilocytic astrocytomas occurring elsewhere in the brain.

Ganglioneuromas of the neurohypophysis would appear to be very much less common. One example, reported briefly by Benda (1927) and subsequently in greater detail by Casper (1933), was an incidental finding at necropsy in a woman, 72 years of age. The tumour, $6 \times 11 \mathrm{~mm}$., destroyed the posterior lobe of the pituitary gland but the anterior lobe was intact. Although the tumour projected above the level of the sella turcica, it was not attached to the brain; its relationship to the hypophyseal stalk was not determined. On histological examination, the tumour was found to contain numerous large and small neurones, many of which were binucleate, and axons and glial elements. Occasional clusters of small, dense nuclei were observed, and thought to represent immature neural elements.

A search of the recent literature has failed to reveal additional similar cases.

\section{CASE REPORT}

A.M., a 45-year-old housewife, was admitted to the Kingston General Hospital on 20 February 1963, for investigation of intractable headaches. These had been present for five years and had gradually increased in

${ }^{1}$ This work was supported by a research grant from the National Cancer Institute of Canada. severity. They were localized mainly in the right frontotemporal area and sometimes spread to involve the area? of the right maxillary eminence. At times they were severe enough to prevent sleep. Many analgesics had been $\frac{\bar{c}}{\frac{1}{7}}$ tried without satisfactory effect. The patient had come to $\mathbb{\otimes}$ depend upon whisky for relief of this head pain. There were no visual symptoms. The patient's menses had been ${ }^{\infty}$ irregular for three years before admission with inter- $\overrightarrow{0}$ mittently a heavy flow. She had had two children, the last born 12 years ago.

On physical examination she appeared depressed and $\stackrel{\circ}{\circ}$ anxious. There was no abnormality on neurological or 3 general physical examination. The visual fields were fullo on perimetry. It was initially felt that this woman might $\mathrm{N}$ well suffer from tension headaches. However, sküi $\omega$ radiographs revealed an enlarged sella turcica. A pneume-i encephalogram showed a convex diaphragma sellae wi a small suprasellar space-occupying lesion projectiog above the diaphragma sellae. There was no alteration or elevation of the anterior recesses of the third ventricte. $\bar{C}$ Bilateral carotid angiograms showed slight straightenipg of the siphon of the internal carotid artery bilatera迹 $\Phi$ which was more marked on the left than the right side $\overrightarrow{0}$

On 27 February 1963 a right frontal craniotomy was performed. When the right frontal lobe had been retracted sufficiently to reveal the region of the sella turcica, a meaty, red tumour mass was seen coming up out of the sellae between the optic nerves and extending superiorly and anteriorly partially to enfold the anterior aspect of $\nsim$ the optic chiasm. The capsule of the tumour was incised $\stackrel{\odot}{\circ}$ and its contents were removed piecemeal. It was then possible to remove all the capsule that could be visualized $\bar{O}$ and to verify the fact that the tumour in fact did arise in 3 the sella turcica and was in no way attached to or coming from the overlying hypothalamus. The patient's post-? operative course was satisfactory except for an episode during the fifth and sixth post-operative days when she became cold and clammy and developed rather profuse :sweating. She had a subnormal temperature during those two days. One week after operation the protein-bound iodine was $4.2 \mathrm{mg} . \%$. Serum electrolytes were normal. Two weeks after operation $17-$ ketosteroids were $12 \cdot 3 \mathrm{mg}$. per 24 hours with a 24-hour urine volume of $1,975 \mathrm{ml}$. 욱 The protein-bound iodine was below normal at $3.2 \mathrm{mg}$. \%. At that time she commenced taking $0.1 \mathrm{mg}$. of Eltroxin per day. Five months after operation the protein-bound iodine level was $6.0 \mathrm{mg}$. \%. Seven and a half months after $\widetilde{N}$ operation 18-ketosteroids were $7.7 \mathrm{mg}$. per 24 hours with urine volume, $1,800 \mathrm{ml}$. 
The patient was discharged from hospital two and a half weeks after surgery. During the first three months following discharge she had moderately severe anorexia and nausea and some intermittent pain behind the right eye. When last seen on 27 September 1963, some seven months after operation, she reported herself as feeling better than she had for many years. Her appetite had returned and she had regained her pre-operative weight. She complained of only the occasional slight ache behind the right eye when fatigued. Neurological examination, including careful assessment of visual fields by perimetery, was normal.

\section{PATHOLOGICAL FINDINGS}

GROsS Several tiny fragments of soft, friable pink tissue weighing a total of about $0.5 \mathrm{~g}$. were received.

LIGHT MICROSCOPY The specimen was embedded in paraffin and stained using standard techniques.

One tissue fragment was composed of a tiny portion of the anterior lobe of the pituitary gland, the architecture and cellular morphology of which was unremarkable.

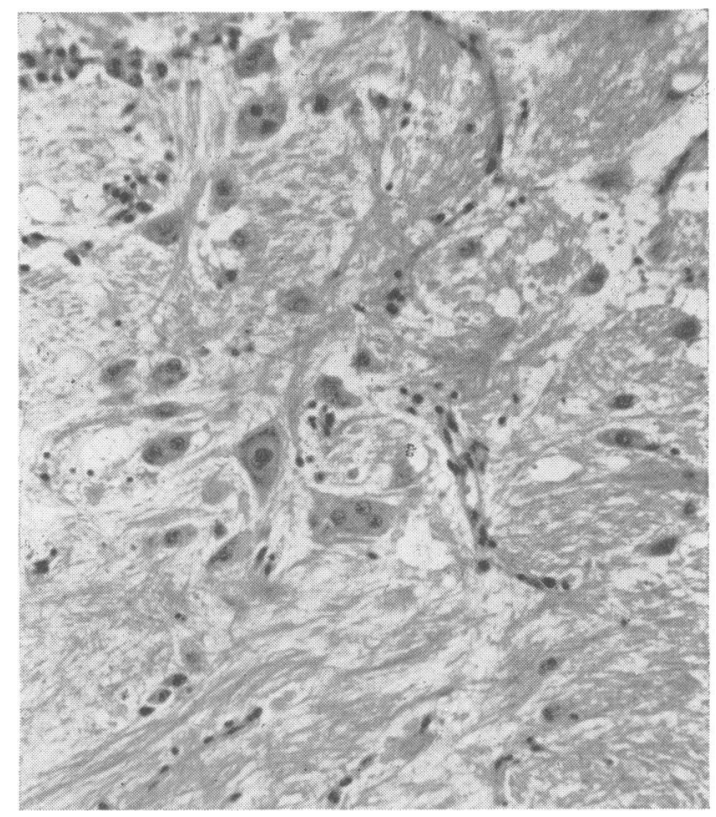

FIG. 1 .
The bulk of the specimen consisted of eosinophilic fibrillar tissue containing clusters of haphazardly arranged multipolar ganglion cells (Fig. 1). These varied greatly in size, but most were large with abundant cytoplasm and large vesicular nuclei. Binucleate and multinucleate cells were frequently encountered. Nissl granules were found in the majority of the cells, usually concentrated near the cell margin (Fig. 2). Coarse processes arising from the perikaryon could be traced for a considerable distance into the surrounding tissue.

In addition, a few smaller cells with dense oval or spherical nuclei were observed, either singly or in small clusters. Their cytoplasm was not readily demonstrable in the routine stains. Although these cells were probably glial elements, their identification was handicapped by the lack of material suitable for specific metallic impregnation. Fibrous astrocytes were not found in phosphotungstic acid-haematoxylin preparations.

Numerous axons of various sizes were demonstrated using the Bodian technique (Fig. 3). Special stains for the demonstration of myelin sheaths were

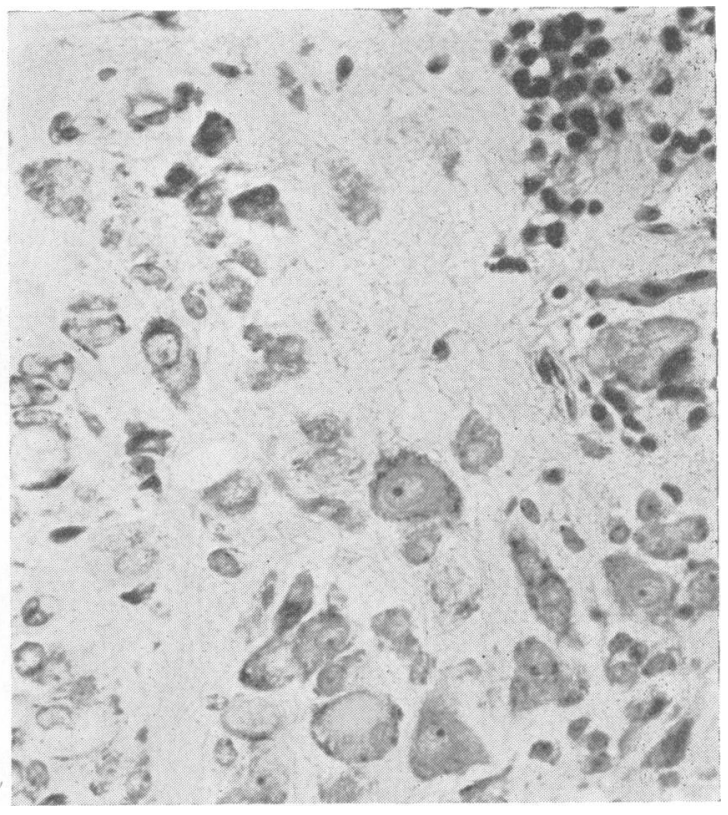

FIG. 2.

FIG. 1. The tumour is composed of many neurones of varying size distributed in a fibrillar stroma. Many of the cells are multinucleated. Processes arising from the cell bodies may be occasionally seen extending into the surrounding tissue. Clusters of small, dense nuclei without visible cytoplasm are frequent, particularly in the vicinity of small blood vessels $(H P S, \times 100)$.

FIG. 2. The neurones have large vesicular nuclei with prominent nucleoli and abundant cytoplasm containing numerous Nissl granules. There is marked variation in the size and shape of the cells (cresyl violet, $\times 250)$. 
negative. Collagen was confined to the perivascular areas, and was small in amount.

ELECTRON MICROSCOPY Tiny fragments of the tumour were fixed in $2 \%$ buffered osmium tetroxide within 15 minutes of removal, embedded in Vestopal (Kurtz, 1961), and examined using a Hitachi HU-11 electron microscope. The tissue was not entirely satisfactory for electron microscopy; there was extensive disruption of cell membranes due perhaps to the trauma of operative removal. Thus, while detailed study of the morphology of the tumour was not practicable, certain observations could be made regarding the nature of the fibrillar background and the structure of the neuronal perikaryon.

The architecture of the tumour as seen by electron microscopy bore some resemblance to normal grey matter in that it consisted of closely packed cytoplasmic processes occupying the space between cell bodies (Fig. 4).

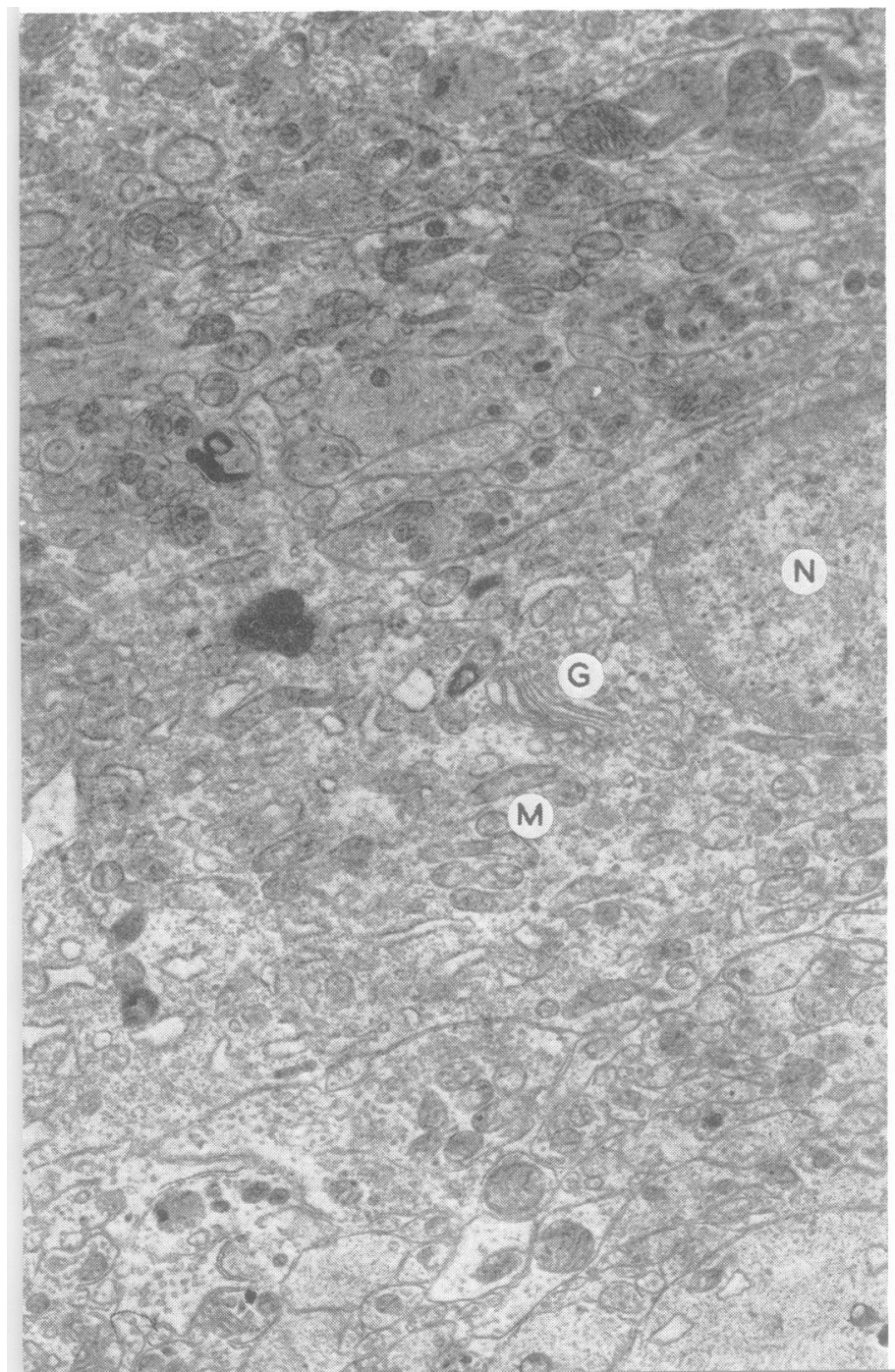

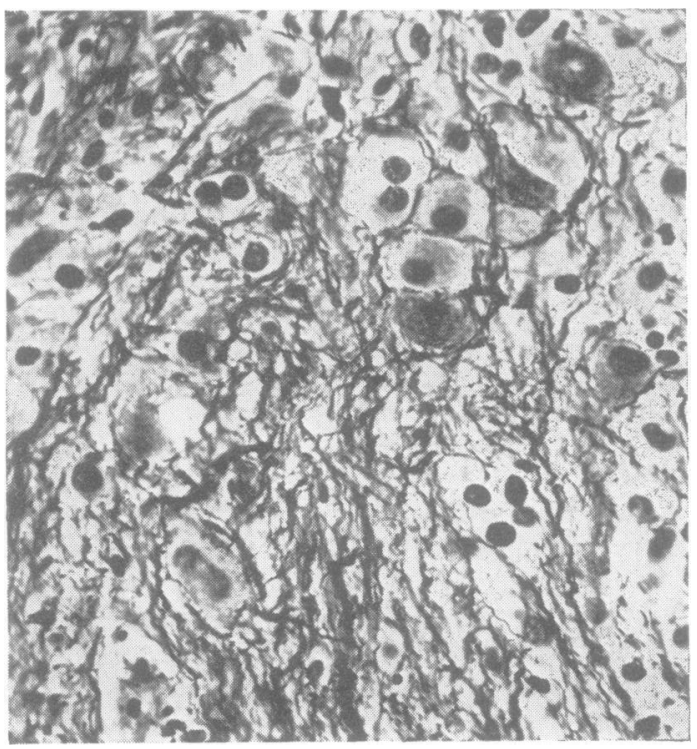

FIG. 3. The tissue between cell bodies contains numerous axons of various sizes, many of which appear tortuous. There is a suggestion of a neurofibrillar network in some of the cells (Bodian, $\times 225$ ).

FIG. 4. A portion of a cell body lies approximately horizontally in the middle of the field, with its nucleus? $(N)$ at the right. Within the cytoplasm are numerous 3 mitochondria $(M)$, tubules of the Golgi apparatus $(G)$, granular endoplasmic reticulum $(E)$, and a lipofuscin $\frac{0}{3}$ granule. On either side of the cell body are numerous cytoplasmic processes closely packed together and cut 윽 in various planes. In some areas the cell membranes $D$ appear discontinuous, probably as a result of rupture during surgical removal (electron photomicrograph, $\times 13,000$ ). 


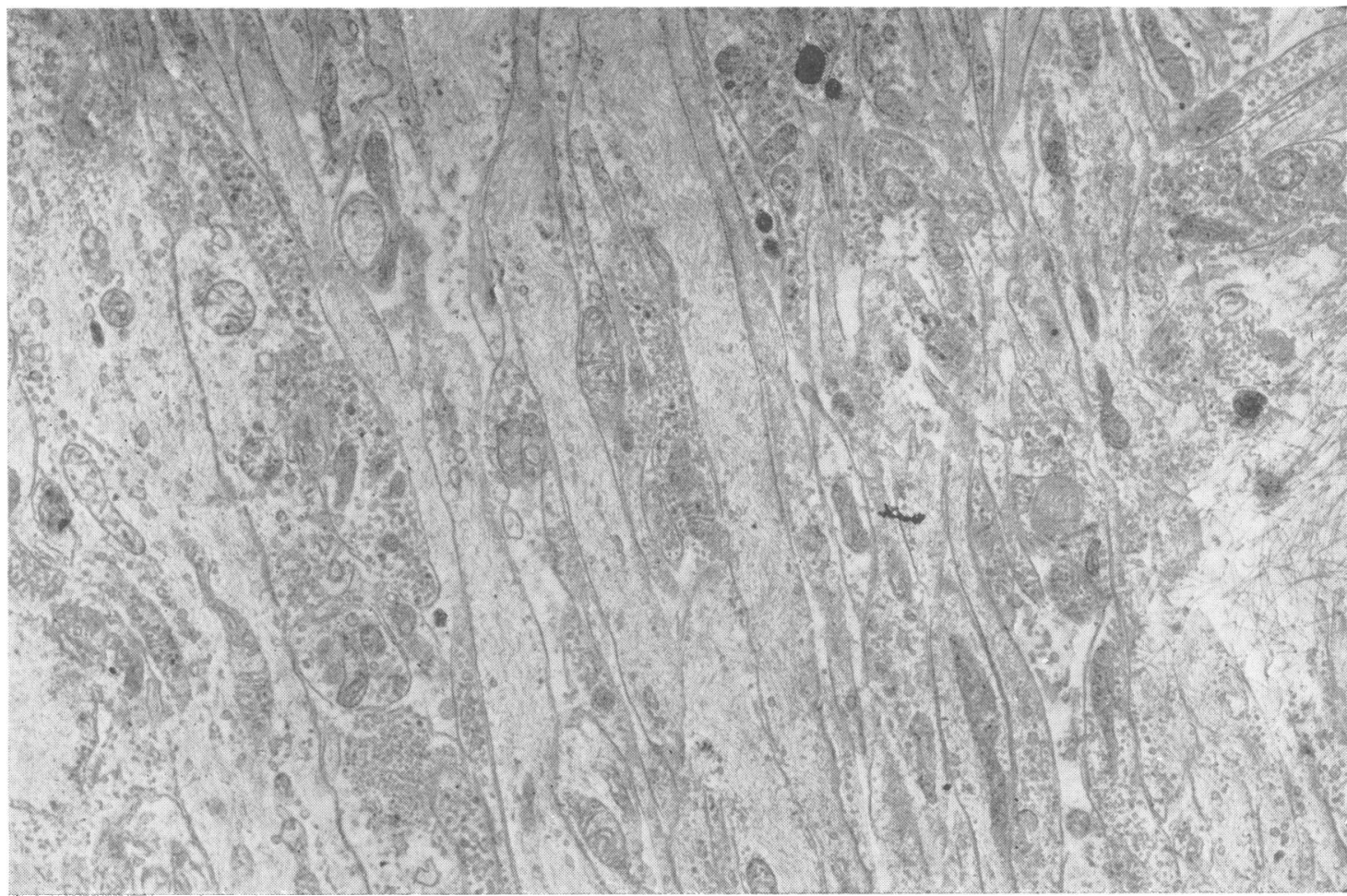

FIG. 5. The neuropil is composed of cytoplasmic processes cut at various angles. Some of the processes contain numerous small vesicles and small mitochondria, while others contain numerous fine rather irregularly arranged fibrils, and occasional vesicles. Near the top of the photograph are a few collagen fibres, which were in relation to a blood vessel $(\times 17,000)$.

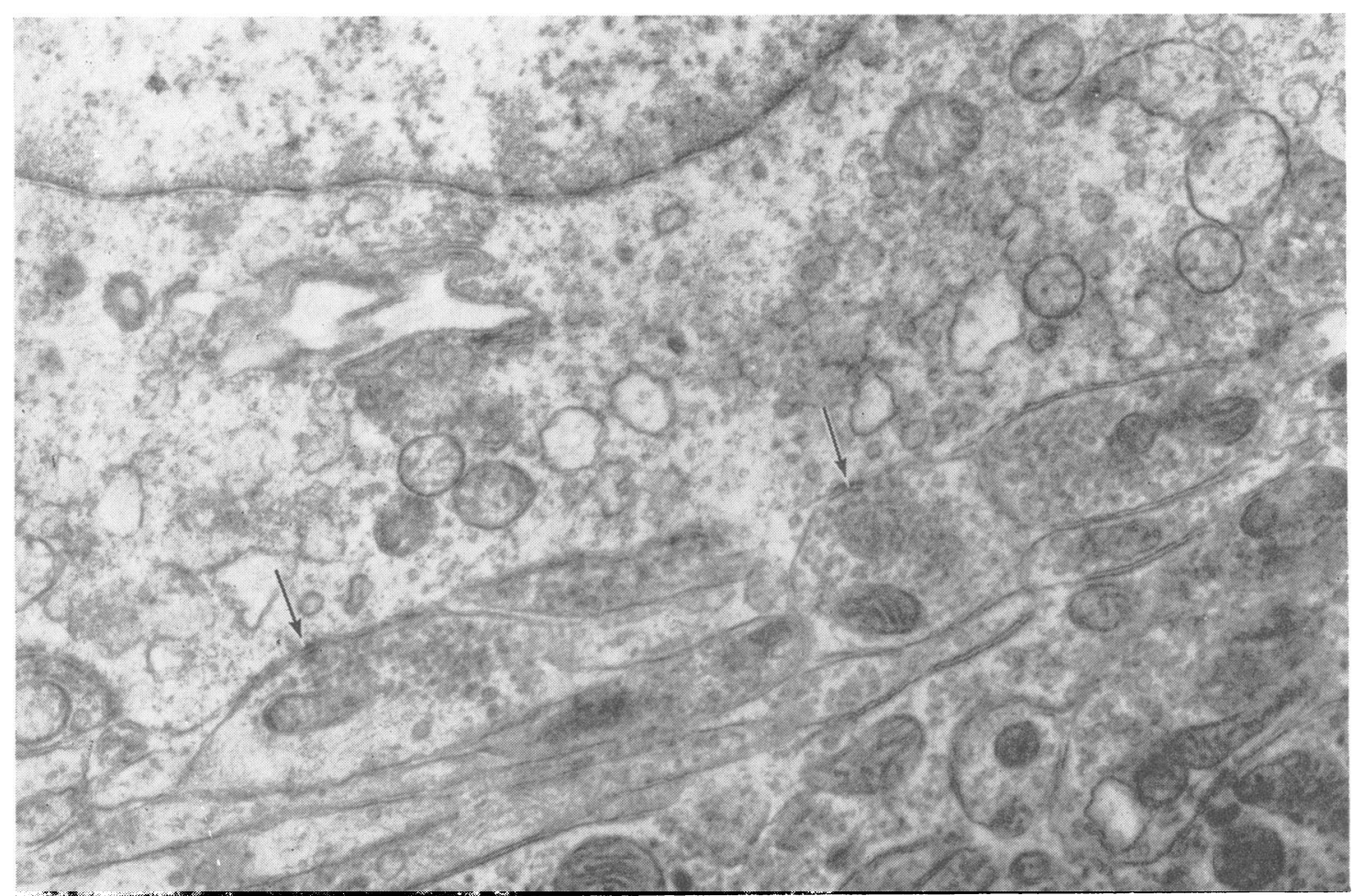

FIG. 6. A portion of a cell body of a neurone occupies the left half of the field, and contains the usual cytoplasmic organelles. Several vesicle containing processes are arrayed along the cell membrane, and at some points there is thickening of the adjacent cell membranes suggestive of synapses (arrows) $(\times 32,000)$. 
The appearance of the neuronal cytoplasm differed from that of normal neurones (Palay and Palade, 1955; Herndon, 1963), particularly in the abundance of mitochondria. The elements of the granular endoplasmic reticulum frequently appeared dilated, but this may have been artefactual. Elements of the Golgi apparatus and lipofuscin granules were frequently seen.

The cytoplasmic processes between cells were of two morphological types (Fig. 5). The first contained large numbers of small, clear, membrane-bound vesicles, small mitochondria, and a few fine fibrils. The appearance of the vesicles was not unlike those found in the presynaptic processes of normal nervous tissue (Gray, 1959; Hamlyn, 1963). The second type of process varied greatly in size, and contained large numbers of fine intracytoplasmic fibrils, occasional vesicles, and mitochondria.

The cell bodies tended to be encompassed by the vesicle-containing processes. Not uncommonly, small segments of the adjacent cell membranes of processes and the perikaryon showed focal thickening and increased osmophilia (Fig. 6), not unlike that described in synapses (Hamlyn, 1963). Usually the 'post-synaptic membrane' was thicker than the 'pre-synaptic membrane'.

\section{DISCUSSION}

The case presented here is one of a tumour-like mass of neurones, glia, and their processes occupying an enlarged sella turcica and extending through the diaphragma sellae into the subarachnoid space beneath the hypothalamus. While it may have been the cause of the patient's headaches, it had not produced demonstrable dysfunction of the anterior lobe of the pituitary gland, neurohypophyseal system, hypothalamus, or optic nerves and radia- tions. It was not attached to the hypothalamus nor did it produce deformity of the third ventricle as seen at pneumoencephalography.

It may be debated as to whether this lesion con-

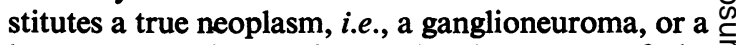
hamartoma. The erosion and enlargement of the $c$ sella turcica would seem to be in favour of pro- $D$ gressive growth of the lesion. However. the distinction between ganglioneuromas and hamartomas is $\frac{\overrightarrow{0}}{0}$ not sharp; so-called hamartomas of neural origin $\overrightarrow{2}$ located above the diaphragm sellae present a similar : problem of nomenclature and may, by enlarging, $\stackrel{\vec{S}}{S}$ encroach on neighbouring structures producing clinical manifestations (Russell and Rubinstein, 1959).

\section{SUMMARY}

A case is described in which a ganglioneuroma was found occupying an enlarged sella turcica. Apart $\vec{\omega}$ from headache, which may have been unrelated to the tumour, there were no clinical manifestations, nor was any significant post-operative alteration demonstrated. Histologically and by electron microscopy the tumour was composed principally of $i$ well-differentiated neurones and their processes.

\section{REFERENCES}

Benda, C. (1927). Verh. dtsch. path. Ges., 22, 185.

Casper, J. (1933). Zbl. allg. Path. path. Anat., 56, 404.

Globus, J. H. (1942). J. Neuropath. exp. Neurol., 1, 59.

Gray, E. G. (1959). J. Anat. (Lond.), 93, 420.

Hamlyn, L. H. (1963). Ibid., 97, 189.

Herndon, R. M. (1963). J. cell. Biol., 18, 167.

Kurtz, S. M. (1961). J. Ultrastruct. Res., 5, 468.

Palay, S. L., and Palade, G. E. (1955). J. biophys. biochem. Cytol., 1, 69.

Russell, D. S., and Rubinstein, L. J. (1959). Pathology of Tumours of the Nervous System, pp. 25, 196. Arnold, London.

Scothorne, C. M. (1955). J. Path. Bact., 69, 109. 